\title{
Identification of resistance gene analogs in Korean wild apple germplasm collections
}

\author{
D.E. Baek and C. Choi \\ Department of Horticulture Sciences, Kyungpook National University, \\ Daegu, Korea \\ Corresponding author: C. Choi \\ E-mail: cc31@knu.ac.kr
}

Genet. Mol. Res. 12 (1): 483-493 (2013)

Received February 1, 2012

Accepted August 31, 2012

Published January 30, 2013

DOI http://dx.doi.org/10.4238/2013.January.30.2

\begin{abstract}
Several plant disease resistance gene (R-gene) classes have been identified on the basis of specific conserved functional domains. Cloning of disease-resistance apple genes would be useful for breeding programs and for studying resistance mechanisms. We used a PCR approach with degenerate primers designed from conserved NBS-LRR (nucleotide binding site-leucine-rich repeat) regions of known R-genes to amplify and clone homologous sequences from six Korean wild apple germplasm collections and an individual plant of the Siberian wild apple, Malus baccata. One hundred and twenty-four sequenced clones showed high similarity at multiple NBS motifs with the R-genes of other plants. The clones OLE 2-9, BP 6-11, OLE 1-22, and OLE 5-13 shared 45\% identity with the R-gene of other plants. The conserved sequence, which plays an important role in resistance, was found in our isolated resistance gene analogs (RGAs). The sequences of isolated apple RGAs showed more similarity to Toll/interleukin-1 receptor (TIR)-NBS-LRR than non-TIR-NBS-LRR. We suggest using a marker for this resistance gene region as well as for identifying potential material for disease-resistant breeding among Korea wild apple germplasms. This is the first step in preparing a comprehensive analysis of the RGAs in Korean wild apple germplasm.
\end{abstract}

Key words: NBS-LRR; Resistance gene analogs; R-gene 


\section{INTRODUCTION}

The apple is one of the most widely cultivated tree fruits in the world. It is important to develop good-quality apple trees with major disease resistances, and the breeding process is tempered by several characteristics of the apple. Apple breeding is difficult and time-consuming because of a long intergeneration period due to its juvenile phase, large plant size, high chromosome number $(2 \mathrm{n}=34)$, and self-incompatibility. Early screening by using molecular genetic technology would result in much more efficient apple breeding programs (Hemmat et al., 1994).

According to a recent survey, the number of diseases and pests in the orchards of this country has increased. The major apple diseases, insects and mite pests in Korea are bitter rot, marssonina blotch, white rot, alternaria blotch, fruit moths, and spider mites (Lee et al., 2007). The development of disease-resistance cultivars is the key to solving these problems.

Plants have an innate immune response, which involves the plant resistance gene (R-gene). This R-gene can defend against attacks from fungi, oomycetes, bacteria, viruses, insect pests, and nematodes. According to a gene for gene model, the R-gene in the host interacts with a cognate avirulence (Avr) gene in the pathogen and triggers the chain of defense responses associated with hypersensitive response (Flor, 1971; Dangl and Jones, 2001). These genes have been identified on the basis of specific conserved functional domains and grouped into five diverse classes (Hammond-Kosack and Jones, 1997). The NBS (nucleotide-binding site)-LRR (leucine-rich repeat) family is not only the most abundant class but also shows resistance to a number of pathogens.

The NBS domain located at the N-terminal end contains several highly conserved motifs, such as the P-loop/kinase 1, kinase 2 and kinase 3-a and hydrophobic GLPL. P-loop (phosphate-binding loop) is a motif in ATP- and GTP-binding protein involved with an ATP synthase $\beta$ subunit, ras protein, ribosomal elongation factor, and adenylate kinase with molecular switches (Saraste et al., 1990; Bourne et al., 1991). GLPL is a putative membranespanning domain. The C-terminal end of the LRR domain is a 20-29 residue sequence motif that offers a structural framework for the formation of protein-protein interactions (Kobe and Deisenhofer, 1994). NBS-LRR is divided into two subfamilies by an upstream domain. One subfamily contains a domain that is similar to the Drosophila Toll and mammalian interleukin-1 receptor (TIR) protein associated with innate immunity. The other subfamily, without TIR, is called non-TIR and often contains a coiled-coil motif.

The PCR approach with degenerate primers is based on conserved amino acid motifs of a known NBS-LRR gene. This method has been widely used to find NBS-encoding disease resistant gene analogs (RGAs) from a variety of species, including Arabidopsis thaliana (Aarts et al., 1998), tomatoes (Leister et al., 1996), soybeans (Yu et al., 1996), and lettuce (Shen et al., 1998), as well as plants such as Rosaceae fruit crops, Prunus (Lalli et al., 2005; Soriano et al., 2005), apples (Lee et al., 2003; Baldi et al., 2004), and strawberries (Martinez Zamora et al., 2004).

Our long-term objective is to breed a multiple disease-resistant cultivar that is protected against Korean apple industry problem diseases. This has prompted us to analyze the RGAs that occur in local collections of apple germplasms in Korea. These findings will help select a parent for future multiple disease-resistant apple cultivars. In the present study, we used a PCR cloning strategy with degenerate primers to successfully amplify NBS sequences from the genome of local apple germplasm collections. The RGAs from Korean local apple germplasm 
collections were investigated for their diversity to gain insights into the evolution of the TIRNBS-LRR genes and their potential use in disease-resistant apple breeding in Korea.

\section{MATERIAL AND METHODS}

\section{Plant material}

Plant materials were obtained from Korean wild apple germplasm collections at the Apple Research Station located in Gunwigun, Korea. Six Korean wild apple germplasms, 'KW-CA-1' from Mt. Chiak, Gangwon-do, 'KK-BH-2-1' from Mt. Bukhan, Gyeonggi-do, 'KN-GY-4' from Mt. Gaya, Gyeongnam, 'KP-PG-4' from Mt. Palgong, Gyeongbuk, 'KWJB-1' from Mt. Palgong Gyeongbuk, 'JJ-HL-8' from Mt. Halla Jeju-do, and Malus baccata Borkh. from the USDA (United States Department of Agriculture) Plant Genetic Resources Unit were used in this study. Genomic DNA was extracted from young leaves using a modification of the CTAB method (Torres et al., 1993).

\section{PCR amplification of RGA sequences}

Two R-gene-specific degenerate oligonucleotide primers were used. The first selected primers, OLE 1121 (5'-GGWATGGGWGGWRTHGGWAARACHAC-3') and OLE 1122 (5'-ARNWYYTTVARDGCVARWGGVARWCC-3'), were designed according to the conserved P-loop (GGVGKTT) and hydrophobic domain (GLPLAL) from the RPS2, RPS5, and L6 Xa1 genes of the NBS-LRR class, which is specific against pathogens (Lee et al., 2003). The second selected primers, BP2f (5'-GGNGGDGTDGGSAARAC-3') and BP2r (5'-GCTAGTGGCAMNCCWCC-3'), were designed according to Baldi et al. (2004).

PCR was carried out in a total volume of $40 \mu \mathrm{L}$, containing $3.2 \mu \mathrm{L} 10 \mathrm{mM}$ dNTP mixture, 20 pmol of each primer, 10X reaction buffer, $60 \mathrm{ng}$ DNA, and 2 U Taq DNA polymerase (Genet Bio). PCR was performed in a TP600 DNA thermal cycler (Takara, Japan). The following conditions were used: an initial denaturation step at $94^{\circ} \mathrm{C}$ for $3 \mathrm{~min}$ and 40 cycles consisting of denaturation at $94^{\circ} \mathrm{C}$ for $30 \mathrm{~s}$, annealing at $50^{\circ} \mathrm{C}$ for $45 \mathrm{~s}$, and extension at $72^{\circ} \mathrm{C}$ for $1 \mathrm{~min}$, with a final extension step of $72^{\circ} \mathrm{C}$ for $8 \mathrm{~min}$. PCR products were analyzed by electrophoresis on $1.5 \%$ agarose gels in $1 \mathrm{X}$ TBE, which were stained with ethidium bromide and visualized under UV light.

\section{Cloning and sequencing}

Bands of the expected size (approximately $500 \mathrm{bp}$ ) were excised from gels using a GENECLEAN turbo kit (MPbio). The eluted fragments were cloned into the pGEM-T easy vector (Promega) and transformed into Escherichia coli DH5 $\alpha$ competent cells by electroporation. The clones were screened by blue/white colony selection, following manufacturer instructions. Fifty-two or fewer colonies were selected from each individual apple collection and primer combination.

Colony PCR was performed using the forward primer T7 and the reverse primer SP6. Each PCR product was digested using SacI (Promega) and HaeIII (Enzynomics). Some clones showing very similar restriction patterns were chosen for sequencing. 
Selected colonies were incubated overnight at $37^{\circ} \mathrm{C}$ in LB broth medium containing $100 \mu \mathrm{g} / \mathrm{mL}$ ampicillin. Plasmid DNA was isolated using a plasmid DNA purification miniprep kit (Promega). After isolation, the insert sequence was sequenced with an ABI377 automated sequencer and the ABI Prism BigDye terminator cycle sequencing-ready reaction kit (Applied Biosystems, Foster City, CA, USA), following recommended protocols.

\section{RGA sequence alignment and phylogenetic analysis}

Isolated RGA sequences were compared with a public database by using BLAST (Basic Local Alignment Search Tool: http://blast.ncbi.nlm.nih.gov/Blast.cgi). DNA sequence translations were determined with the EMBOSS transeq (http://www.ebi.ac.uk/ Tools/st/emboss transeq).

Phylogenetic neighbor-joining analyses of nucleotide sequences were performed using the Molecular Evolutionary Genetics Analysis (MEGA) version 4.0 software (Tamura et al., 2007). The tree branches were evaluated using the bootstrap method (Felsenstein, 1985).

The deduced amino acid sequences of RGAs were aligned with known NBS domains of R-genes using ClustalW (http://www.ebi.ac.uk/Tools/msa/clustalw2/) and edited with the GeneDoc software (Nicholas and Nicholas, 1997).

\section{RESULTS}

\section{Isolation of RGAs from apples by PCR amplification with degenerate primers}

The two pairs of degenerate primers, which corresponded to the P-loop motif and the GLPLAL motif of NBS-LRR proteins, generated PCR products with six Korean apple germplasm collections and M. baccata, ranging in size from 300 to $700 \mathrm{bp}$. A total of 313 putative apple RGA clones were produced. They had sizes of 510-520 bp, which were similar to those expected based on the size of the targeted NBS domain in the NBS-LRR R-genes from other plants, which were isolated and sequenced from six Korean germplasm collections and M. baccata. Nine of the 313 putative clones were identical sequences. Accordingly, the same sequences were excluded from the analysis. All unique sequences were explored in the GenBank database (http://www.ncbi.nlm.nih.gov) by using the nucleotides BLAST and BLASTX to analyze significant homology within the NBS-LRR sequences. One hundred and sixty-four of 304 sequence fragments gave DNA sequence information with a high level of accuracy to NBS domain sequences, but other sequences showed no significant similarity or were unrelated to the resistance gene in the GenBank database. When the sequences were translated into amino acid sequences, 40 of these RGAs contained stop codons and/or frameshift mutations. Therefore, they were excluded from later analysis. A total of 124 sequences were identified as final RGAs. The nucleotide sequences of isolated wild apple RGAs have been deposited in the GenBank database under accession Nos. HQ398999 to HQ399127. All these results are shown in Table 1. Identified clones were named as primer sets (i.e., BP or OLE), apple germplasm collections (1: M. baccata; 2: 'KW-CA-1'; 3: 'KK-BH-2-1'; 4: 'KN-GY-4'; 5: 'KP-PG-4'; 6: 'KW-JB-1', and 7: 'JJHL-8'), and clones. 


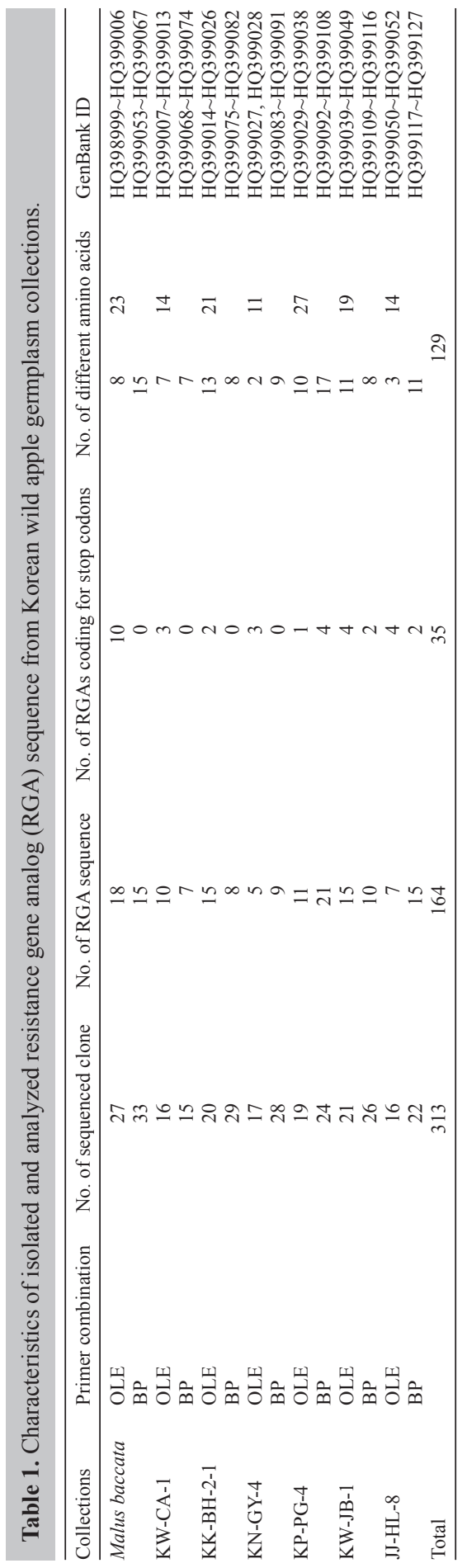




\section{Diversity analysis of Korean wild apple RGAs}

The score of nucleotide identity among apple RGAs ranged between 13.8\% (OLE 5-7, OLE 7-6) and 90.5\% (BP 5-5, BP 7-10). In the case of identity scores for amino acid sequences, they ranged between 12.5\% (OLE 1-13, BP 4-27) and 100\% (OLE 1-13, OLE 2-4; BP 1-2, BP 1-21; BP1-9, BP 4-22; BP 1-14, BP 1-18; BP 2-13, BP 5-10; BP 3-6, BP 5-1; BP 5-7, BP 5-23). The predicted amino acid RGA sequences were determined using a phylogenetic tree based on the neighbor-joining method. As shown in Figure 1, 124 RGA sequences were classified into two major groups, 95 sequences of the TIR type and 29 sequences of the non-TIR type. RGAs of the TIR type were grouped into three secondary groups, which were highly similar to each other, more so than RGAs of the non-TIR type.

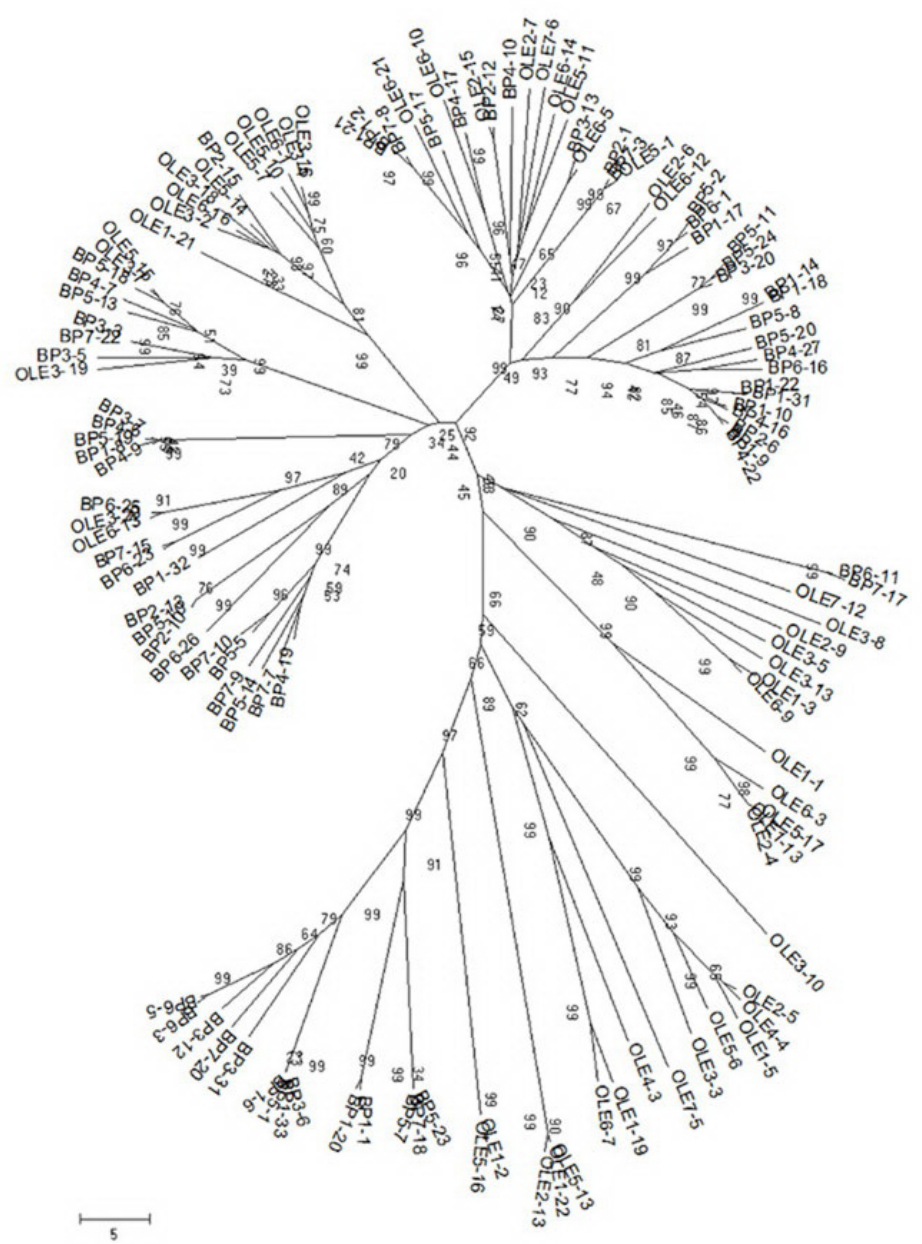

Figure 1. Neighbor-joining phylogenetic tree based on the amino acid sequence of the nucleotide binding site domain for resistance gene analog nucleotide sequences isolated by degenerated primers (BP or OLE sets) from Korean wild apple germplasms (1: Malus baccata; 2: 'KW-CA-1'; 3: 'KK-BH-2-1'; 4: 'KN-GY-4'; 5: 'KP-PG-4'; 6: 'KW-JB-1', and 7: 'JJ-HL-8'). The numbers on the branches represent bootstrap values for 1000 replications. 


\section{Comparative analysis of Korean wild apple RGAs and known R-genes}

The NBS analogs isolated in the present study were compared with known NBSLRR class R-genes, namely the N gene (AAA50763.1) of tobacco, RPP5 (AAF08790), RPS4 (AT5G45250), RPS2 (BAC41890), RPS5 (AAC26126.1), and RPM1 (NP 187360.1) of $A$. thaliana, and L6 (AAA91021.1) of flux in the NBS region, using ClustalW. All sequences were divided into TIR-type and non-TIR-type categories. The alignments of the deduced amino acid sequences showing $80 \%$ identity with one another are shown in Figures 2 and 3 . The multiple alignments of the amino acid sequences of the 43 RGAs had four other conserved regions, which are also observed in the NBS domain of R-genes. These are shown at the top of the alignment and labeled with Roman numerals: I - P-loop/kinase 1, II - kinase 2, III - kinase 3a, and IV - GLPL. The non-TIR group showed the sequence of a tryptophan residue (W) at the end of the kinase 2 motif, while the TIR group mostly had aspartic acid (D) at this position (Meyers et al., 1999). The resulting neighbor-joining phylogenetic tree of the deduced amino acid sequence for RGAs and R-genes is shown in Figure 4. Part A had high similarity with the R-gene of the TIR type. Above all, OLE 2-9 shared a 45\% identity with N, $41 \%$ with M, and $38 \%$ with RPP5. Also, BP 6-11 shared 45\% identity with N, 41\% with M, and 35\% with RPP5. A high degree of identity was observed between part B and the R-genes of the non-TIR type. This B part was detected only by the OLE primer combination. OLE $1-22$ and OLE 5-13 were 52\% identical to RPS5 and 45\% identical to RPS2. OLE 1-19 and I2 shared 45\% of their identities.

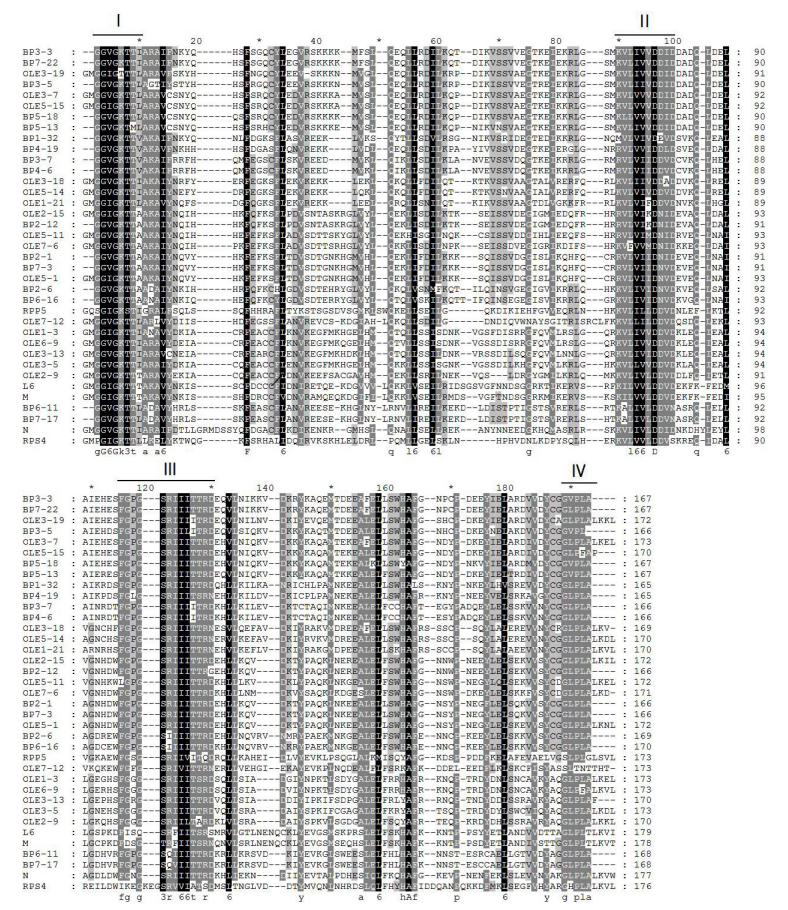

Figure 2. Multiple amino acid sequence analysis of the Toll/interleukin-1 receptor-nucleotide binding site-leucinerich repeat (NBS-LRR) of Korean wild apple resistance gene analogs in comparison with known NBS-LRR class R-genes, $N$ gene (AAA50763.1) of tobacco, RPP5 (AAF08790), RPS4 (AT5G45250), RPS2 (BAC41890), RPS5 (AAC26126.1), and RPM1 (NP_187360.1) of Arabidopsis thaliana and L6 (AAA91021.1) of flux. 


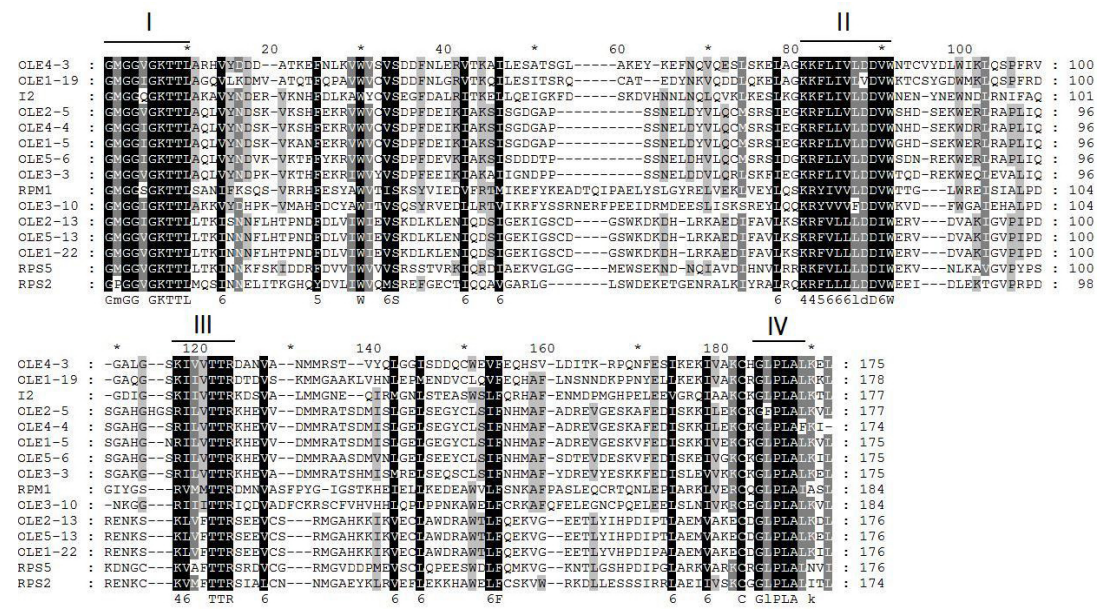

Figure 3. Multiple amino acid sequence analysis of the non-Toll/interleukin-1 receptor-nucleotide binding siteleucine-rich repeat (NBS-LRR) of Korean wild apple resistance gene analogs in comparison with known NBSLRR class R-genes, I2 gene (AF118127.1) of tomato and RPM1 (NP_187360.1), RPP5 (AAF08790), RPS2 (BAC41890) of Arabidopsis thaliana.

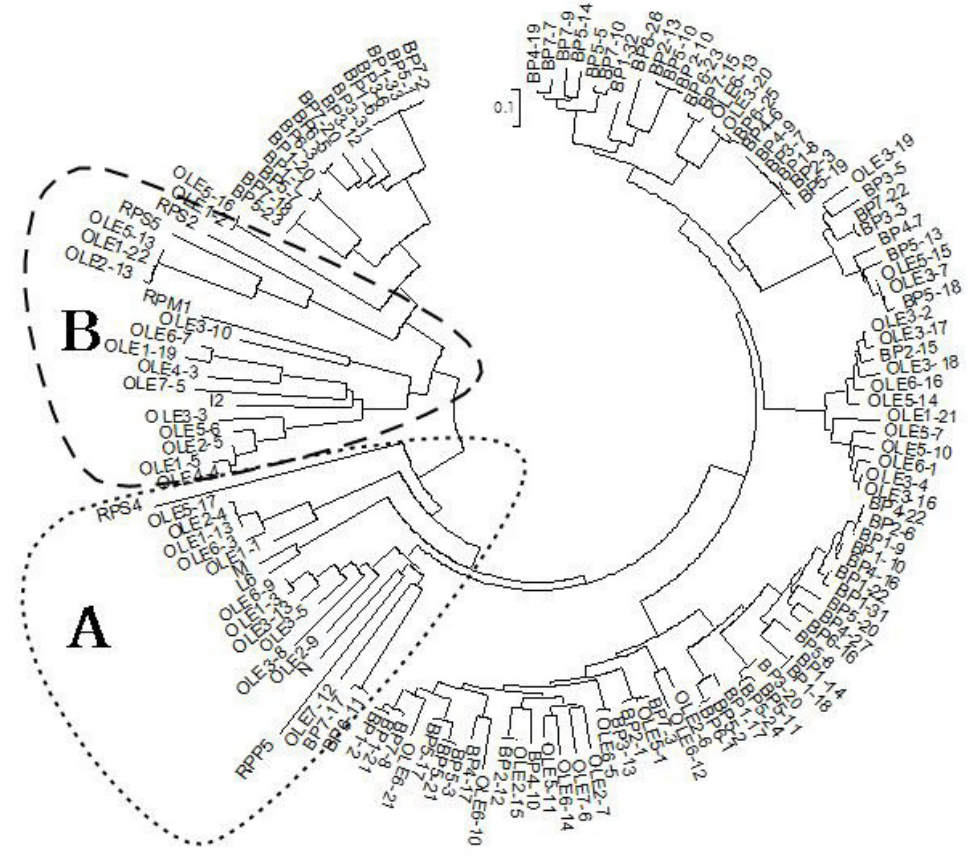

Figure 4. Phylogenetic tree of Korean wild apple resistance gene analogs with known nucleotide binding siteleucine-rich repeat class R-genes, $N$ gene (AAA50763.1) of tobacco, RPP5 (AAF08790), RPS4 (AT5G45250), RPS2 (BAC41890), RPS5 (AAC26126.1), and RPM1 (NP_187360.1) of Arabidopsis thaliana, L6 (AAA91021.1) of flux and the $I 2$ gene (AF118127.1) of tomato. Sequences were aligned using Clustal W, and the tree was generated using the neighbor-joining method. Groups A and B correspond to Toll/interleukin-1 receptor (TIR) and non-TIR disease resistance gene subfamilies, respectively. 


\section{DISCUSSION}

Breeding for disease resistance is one of the most important factors in breeding programs. The use of molecular techniques can be a useful tool in marker-assisted selection and the map-based cloning of genes related to resistance response. PCR approaches with degenerate oligonucleotide primers designed from the NBS region of cloned disease-resistance genes have led to the cloning of similar sequences from many plant species, such as soybeans (Yu et al., 1996), rice, and A. thaliana (Aarts et al., 1998) as well as tomatoes (Pan et al., 2000) and peas (Timmerman-Vaughan et al., 2000). Correlation or co-segregation of some of these sequences with known disease-resistance gene loci has been documented. By using two pairs of degenerate primers matching conserved motifs from the NBS domains of NBS-LRR R-genes from various species, we successfully isolated and characterized 124 RGAs from Korean wild apple germplasm collections and M. baccata in this study. The 124 clones we found were truly RGA sequences due to these sequencing-containing uninterrupted ORFs and the conserved motif characteristics of NBS-LRR R-genes (Lee et al., 2003). Also, it was found that apple germplasm RGAs were closely related to the NBS sequences of $A$. thaliana (Aarts et al., 1998) and tomatoes (Leister et al., 1996).

The NBS-LRR class of resistance genes is widely distributed among plant species. The Arabidopsis genome is estimated to contain approximately 200 genes that encode related NBS motifs, and the distribution of these sequences in the plant is wide (Meyers et al., 1999). The matching Avr gene in the plant will be caused by the loss or mutation of the R-gene. As a result, the plant and pathogen can evolve competitively (Van der Hoorn et al., 2002). Therefore, it is likely that wild apples have more RGAs, which relate to a resistance response. Using BLAST, the predicted amino sequences of Korean wild apple germplasm RGAs were found to have a conserved domain within a protein sequence of known R-genes. Almost all of them included an AP-ATPase clade within the class of P-loop NTPase domain. In fact, P-loop NTPase domains have been detected in approximately $5-10 \%$ of the predicted gene products that sequenced the prokaryotic and eukaryotic genomes (Koonin et al., 2000). AP-ATPase is believed to function as a pathogen recognition protein that triggers the death of pathogeninfected cells. Therefore, it is reasonable to suppose that some of RGAs may have resistant gene products of unknown specificity.

Most of the RGA clones in the apple germplasm collections were grouped within the TIR type, and only 11 RGA clones of 124 clones were grouped within the non-TIR type. These findings were similar to those of previous studies in Rosaceae (Lee et al., 2003; Baldi et al., 2004; Martinez et al., 2004). The source of genetic variation within R-genes has been the subject of recent discussion (Noir et al., 2001). Several genetic mechanisms, including point mutation, recombination, unequal crossing-over, and/or gene conversion, have been proposed to account for the evolution of R-genes (Michelmore and Meyers, 1998). Recently, a detailed analysis of coffee RGA families suggested that point mutations are the primary source of diversity (Noir et al., 2001).

Several studies have reported that the NBS-LRR sequences map near-resistance QTL and loci such as apple scab (Baldi et al., 2004), bacterial spot resistance (Lee et al., 2003), and powdery mildew (Dunemann et al., 2007). It is suggested that a possible approach would be to use a marker in the resistance gene region as well as in potential material for breeding between germplasm collections. The present study demonstrated that degenerate primers based 
on conserved domains of resistance genes can be used to isolate analogous sequences in Korean apple germplasm collections. The 124 RGAs identified in this study can be used to clone and characterize R-genes in Korean apple germplasms and related plant species. This is the first study aimed at analyzing the diversity of RGAs within the genome of Korean wild apple germplasms to understand the role of potential R-genes within fruit trees.

\section{ACKNOWLEDGMENTS}

Research supported by the Export Promotion Technology Development Program, Ministry for Food, Agriculture, Forestry and Fisheries, Republic of Korea.

\section{REFERENCES}

Aarts MG, te Lintel HB, Holub EB, Beynon JL, et al. (1998). Identification of R-gene homologous DNA fragments genetically linked to disease resistance loci in Arabidopsis thaliana. Mol. Plant Microbe Interact. 11: 251-258.

Baldi P, Patocchi A, Zini E, Toller C, et al. (2004). Cloning and linkage mapping of resistance gene homologues in apple. Theor. Appl. Genet. 109: 231-239.

Bourne HR, Sanders DA and McCormick F (1991). The GTPase superfamily: conserved structure and molecular mechanism. Nature 349: 117-127.

Dangl JL and Jones JD (2001). Plant pathogens and integrated defence responses to infection. Nature 411: 826-833.

Dunemann F, Pell A, Urbanietz A and Garcia-Libreros T (2007). Mapping of the apple powdery mildew resistance gene P11 and its genetic association with an NBS-LRR candidate resistance gene. Plant Breed. 126: 476-481.

Felsenstein J (1985). Confidence limits on phylogenesis: an approach using the bootstrap. Evolution 39: 783-791.

Flor HH (1971). Current status of the gene-for-gene concept. Annu. Rev. Phytopathol. 9: 275-296.

Hammond-Kosack KE and Jones JD (1997). Plant disease resistance genes. Ann. Rev. Plant Physiol. Plant Mol. Biol. 48: 575-607.

Hemmat M, Weeden NF, Manganaris AG and Lawson DM (1994). Molecular marker linkage map for apple. J. Hered. 85: 4-11.

Kobe B and Deisenhofer J (1994). The leucine-rich repeat: a versatile binding motif. Trends Biochem. Sci. 19: 415-420.

Koonin EV, Wolf YI and Aravind L (2000). Protein fold recognition using sequence profiles and its application in structural genomics. Adv. Protein Chem. 54: 245-275.

Lalli DA, Decroocq V, Blenda AV, Schurdi-Levraud V, et al. (2005). Identification and mapping of resistance gene analogs (RGAs) in Prunus: a resistance map for Prunus. Theor. Appl. Genet. 111: 1504-1513.

Lee SW, Lee DH, Choi KH and Kim DA (2007). A report on current management of major apple pests based on census data from farmers. Kor. J. Hort. Sci. Technol. 25: 196-203.

Lee SY, Seo JS, Rodriguez-Lanetty M and Lee DH (2003). Comparative analysis of superfamilies of NBS-encoding disease resistance gene analogs in cultivated and wild apple species. Mol. Genet. Genomics 269: 101-108.

Leister D, Ballvora A, Salamini F and Gebhardt C (1996). A PCR-based approach for isolating pathogen resistance genes from potato with potential for wide application in plants. Nat. Genet. 14: 421-429.

Martinez Zamora MG, Castagnaro AP and Diaz Ricci JC (2004). Isolation and diversity analysis of resistance gene analogues (RGAs) from cultivated and wild strawberries. Mol. Genet. Genomics 272: 480-487.

Meyers BC, Dickerman AW, Michelmore RW, Sivaramakrishnan S, et al. (1999). Plant disease resistance genes encode members of an ancient and diverse protein family within the nucleotide-binding superfamily. Plant J. 20: 317-332.

Michelmore RW and Meyers BC (1998). Clusters of resistance genes in plants evolve by divergent selection and a birthand-death process. Genome Res. 8: 1113-1130.

Nicholas KB and Nicholas HBJ (1997). GeneDoc: A Tool for Editing and Annotating Multiple Sequence Alignments. Available at [http://www.psc.edu/biomed/genedoc]. Accessed August 14, 2010.

Noir S, Combes MC, Anthony F and Lashermes P (2001). Origin, diversity and evolution of NBS-type disease-resistance gene homologues in coffee trees (Coffea L.). Mol. Genet. Genomics 265: 654-662.

Pan Q, Wendel J and Fluhr R (2000). Divergent evolution of plant NBS-LRR resistance gene homologues in dicot and cereal genomes. J. Mol. Evol. 50: 203-213.

Saraste M, Sibbald PR and Wittinghofer A (1990). The P-loop - a common motif in ATP- and GTP-binding proteins. 
Trends Biochem. Sci. 15: 430-434.

Shen KA, Meyers BC, Islam-Faridi MN, Chin DB, et al. (1998). Resistance gene candidates identified by PCR with degenerate oligonucleotide primers map to clusters of resistance genes in lettuce. Mol. Plant Microbe Interact. 11: 815-823.

Soriano JM, Vilanova S, Romero C, Llacer G, et al. (2005). Characterization and mapping of NBS-LRR resistance gene analogs in apricot (Prunus armeniaca L.). Theor. Appl. Genet. 110: 980-989.

Tamura K, Dudley J, Nei M and Kumar S (2007). MEGA4: Molecular Evolutionary Genetics Analysis (MEGA) software version 4.0. Mol. Biol. Evol. 24: 1596-1599.

Timmerman-Vaughan GM, Frew TJ and Weeden N F (2000). Characterization and linkage mapping of R-gene analogous DNA sequences in pea (Pisum sativum L.). Theor. Appl. Genet. 101: 241-247.

Torres AM, Weeden NF and Martín A (1993). Linkage among isozyme, RFLP and RAPD markers in Vicia faba. Theor. Appl. Genet. 85: 937-945.

Van der Hoorn RA, De Wit PJ and Joosten MH (2002). Balancing selection favors guarding resistance proteins. Trends Plant Sci. 7: 67-71.

Yu YG, Buss GR and Maroof MA (1996). Isolation of a superfamily of candidate disease-resistance genes in soybean based on a conserved nucleotide-binding site. Proc. Natl. Acad. Sci. U. S. A. 93: 11751-11756. 